\title{
60 YEARS \\ OF PUBLICATION OF Acta Agrobotanica
}

Acta Agrobotanica was founded in 1953 as one of several scientific journals issued by the Polish Botanical Society. Most papers published thus far in Acta Agrobotanica have been original research papers dealing with the biology of cultivated plants or wild plants accompanying crops. In addition to this type of papers, review articles are also published in the journal.

Throughout the existence of the journal, 8 persons have held the position of Editor-in-Chief: Janina Lekczyńska (for 28 years), Stanisław Wóycicki (18 years), Zofia Starck (10 years), Leszek Jankiewicz (4 years), Marian Saniewski (20 years), Adam Dobrzański (10 years), Janusz Lipecki (6 years), and Elżbieta Weryszko-Chmielewska (9 years).

The following persons have been successively the Editors of Acta Agrobotanica:

Janina Lekczyńska and Stanisław Wóycicki (1953-1970);

Janina Lekczyńska and Zofia Starck (1970-1979);

\author{
Leszek Jankiewicz and Marian Saniewski \\ (1980-1982); \\ Marian Saniewski and Adam Dobrzański \\ (1982-1983); \\ Leszek Jankiewicz and Marian Saniewski \\ (1984); \\ Marian Saniewski and Adam Dobrzański \\ (1985-1992); \\ Marian Saniewski (1993-1998); \\ Janusz Lipecki (1999-2004);
}

Elżbieta Weryszko-Chmielewska (od 2005).

Over this period of 60 years, 1521 original scientific papers have been printed in Acta Agrobotanica. Until 2001, the number of papers published every year was not more than 30 , whereas in 2002 this number almost doubled (56 papers). The largest annual number was published in 2006 (93 papers). The largest number of papers (607) has been published during the last decade of the journal's life (2003-2013) and this accounts for $40 \%$ of all articles (Figure 1).

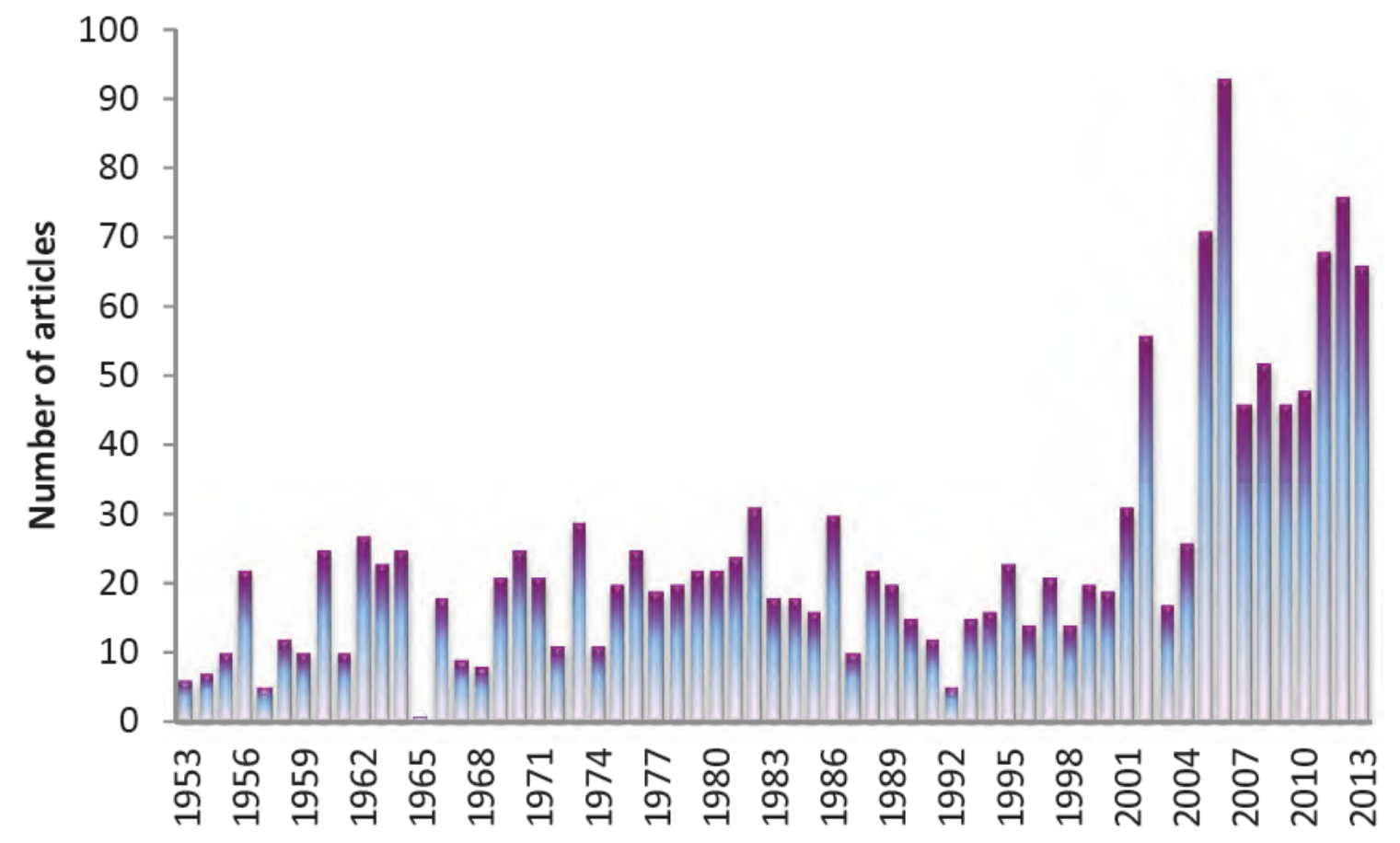

Fig. 1. The number of papers published in Acta Agrobotanica over the period 1953-2013. 
The thematic diversity of papers published in particular decades of the journal's existence is shown in Figure 2. Throughout the first four decades, papers on plant physiology and genetics were predominant, while in the fifth and sixth decades papers on entomology and phytopathology also had a large proportion. Over the last twenty years, publications dealing with new areas: herbology and aerobiology, have appeared. During the last ten years, the percentage of articles on plant anatomy

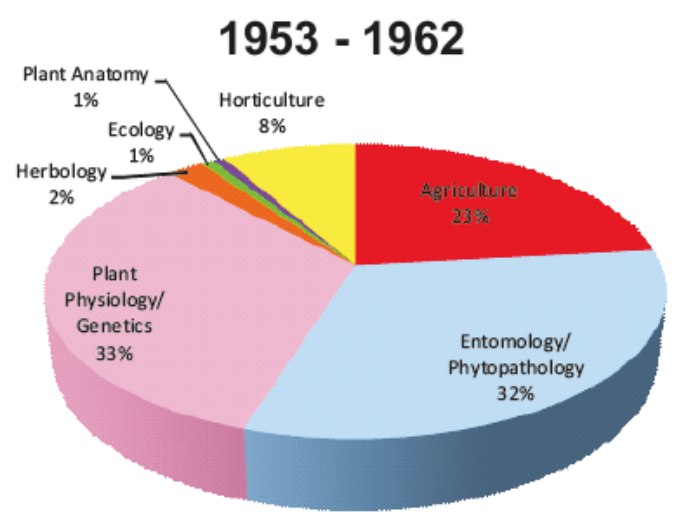

$1973-1982$
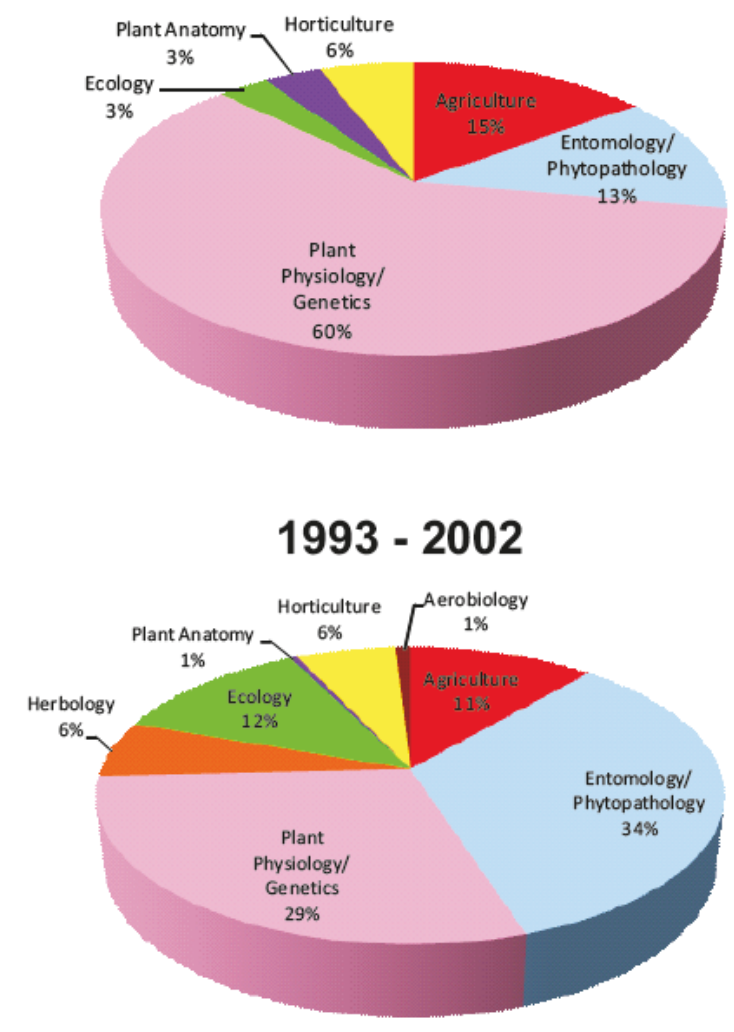

has significantly increased (Figure 2). Over the period 1953-2002, the percentage of papers on plant anatomy published in Acta Agrobotanica was $1-4 \%$, whereas in the period 2003-2013 it reached as much as $17 \%$. In recent years, papers on entomology and phytopathology have also appeared in significant numbers (19\%). Compared to the earlier years, the last decade has been characterized by a certain balance in the proportion of different types of topics of papers published (Figure 2).

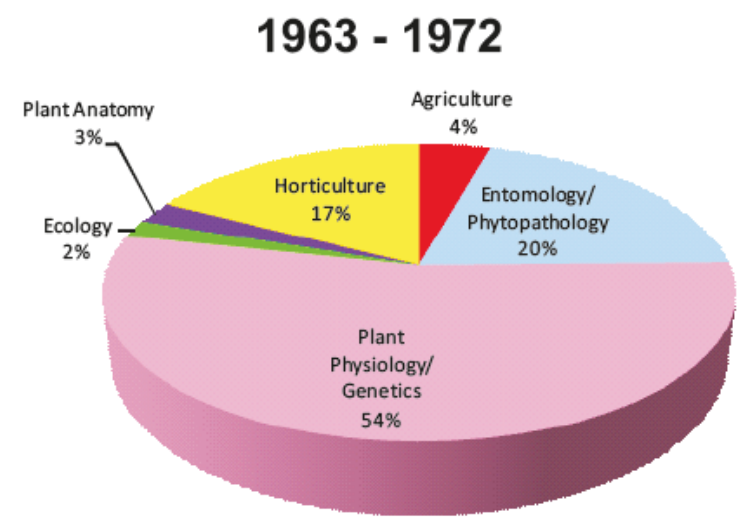

$1983-1992$

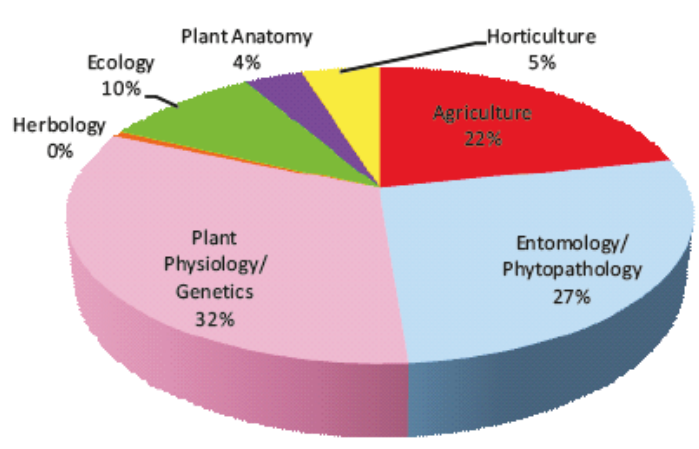

$2003-2013$

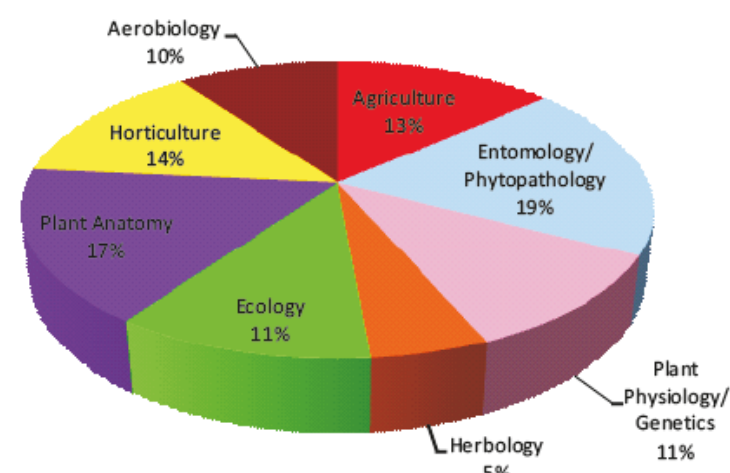

$5 \%$

Fig. 2. Percentages of papers on different topics in successive decades of the journal's existence. 


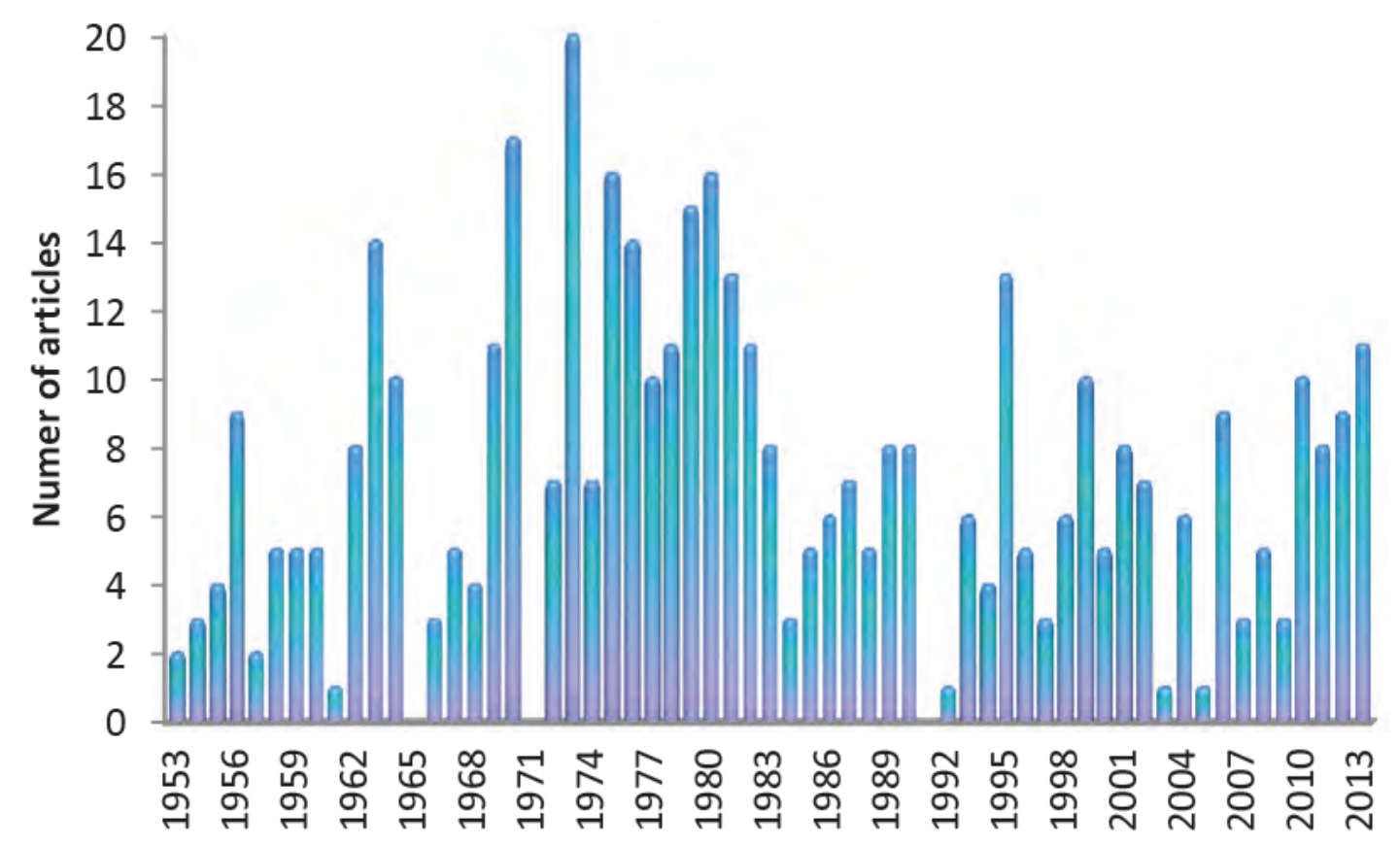

Fig. 3. The number of papers on genetics and plant physiology published in Acta Agrobotanica over the period 1953-2013.

Results of research on plant genetics and physiology have the highest proportion among papers published in Acta Agrobotanica. Figures 2 and 3 show that the greatest number of papers addressing these topics was published in the third decade of the journal's existence. A record number of papers on plant physiology appeared in 1973.

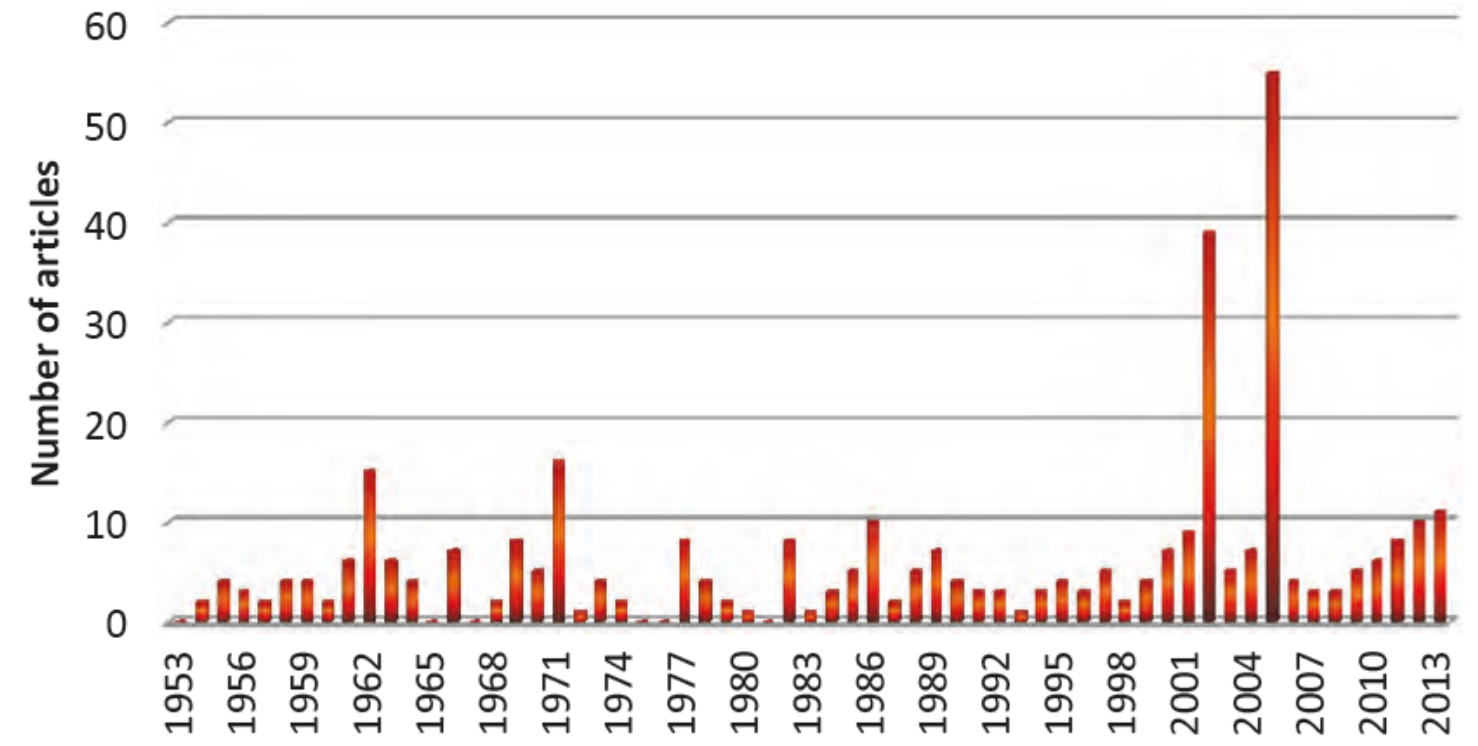

Fig. 4. The number of papers on entomology and phytopathology published in Acta Agrobotanica over the period $1953-2013$.

The number of published papers on entomology (relating to herbivores) and phytopathology ranged from several to a dozen or so in particular years. Exceptionally, in 2002 and 2005 the number of these articles increased markedly and it was respectively 40 and 55 (Figure 4).
The number of manuscripts currently received by the Editorial Board and awaiting publication guarantees the continuity of publication of the next volumes of the journal.

Elżbieta Weryszko-Chmielewska Magdalena Michońska Aneta Sulborska 